\title{
Reciprocity as deliberative capacity: lessons from a citizen's deliberation on carbon pricing mechanisms in Australia
}

\author{
Alex Y Lo \\ Griffith Climate Change Response Program and Urban Research Program, Griffith School \\ of Environment, Griffith University, Gold Coast Campus, QLD 4222, Australia; \\ e-mail: alex.lo@griffith.edu.au
}

Kim S Alexander

Illawarra Health and Medical Research Institute, University of Wollongong, Wollongong, NSW 2522, Australia; e-mail: kalexand@uow.edu.au

\section{Wendy Proctor}

CSIRO Ecosystem Sciences, Clunies Ross Street, Black Mountain, Canberra, ACT 2601, Australia

\section{Anthony Ryan}

The Fenner School of Environment and Society, Australian National University, Canberra, ACT 0200, Australia

Received 13 July 2011; in revised form 22 March 2012

\begin{abstract}
Australia has seen a deep division in opinion in search of a carbon pricing mechanism. While concepts of carbon taxation and emission trading have comparable public support, climate scepticism is influencing the debates in political and public spheres in downplaying the need for carbon pricing. Public deliberation is a possible engagement option to address the conflict inherent in climate policy preferences. This research explores the way that a deliberative forum involving twenty-four Australians promoted effective communication between participants through which conflict between policy preferences became more tangible. While the forum did not eliminate disagreement in preferences in the choice of carbon pricing mechanisms, participants reached consensus on fundamental principles such as the need for trusted sources of information, trusted governance procedures, and transparent accountability by appropriate institutions. Shared political expectations encouraged dialogue and cooperation in discussions by enhancing reciprocal understanding. Two sceptical participants who originally had strong opinions different from the rest of the group managed to find common ground. Public deliberative forums that are conducive to reciprocal communication are able to provide a mechanism for joint problem-solving processes that are less adversarial and more responsive to the range of people's preferences.
\end{abstract}

Keywords: public deliberation, consensus, emission trading, carbon tax, deliberative democracy, Australia

\section{Introduction}

Public opinion on whether global climate change is human induced - and, if so, the most appropriate policy responses - is divergent and changing as the issue evolves. A significant portion of citizens currently dispute climate change estimates, including biophysical effects and sea-level-rise predictions (Alexander et al, 2012; Climate Institute, 2010; Hulme, 2009). Public debate has escalated and in many instances has polarised in response to mass media involvement and political partisanship, biasing representations of the impacts of emission 
trading schemes (ETSs) and casting doubt on economic implications (Pietsch and McAllister, 2010; Spash, 2010). The opinions of climate change sceptics have been found to impact the course of public debate on climate mitigation strategies (Climate Institute, 2010; Leviston and Walker, 2010; Nerlich, 2010; Oreskes and Conway, 2010). The divisive debate poses challenges to effective governance of climate mitigation and adaptation (Amundsen et al, 2010; Few et al, 2007; Hobson and Niemeyer, 2011; Krause, 2011; Osberghaus et al, 2010; Pitt, 2010).

Constitutional institutions that encourage adversarial politics have a tendency to reduce opportunities for parties and individuals to cooperate in search of acceptable policies. Public engagement through dialogue with citizens and stakeholders, such as citizen forums, has been seen as an alternative that can enable collaborative efforts supporting environmental decision making and future planning and/or elicit behavioural change (Alexander, 2010; Marks, 2006; Stangellini, 2010). Deliberative forums can create an effective dialogue between climate change actors (Hobson and Niemeyer 2011; McCrum et al, 2009). Public deliberation promotes social learning through reflection upon preference and assists in reconciling conflict while building cooperative capacity towards consensual outcomes. The concept has risen in prominence in society generally, increasing deliberative democracy by encouraging citizens to be involved in detailing their opinions, finding mutually justifiable reasons, and recognising the values held by others when engaging in policy discussions (Dryzek, 2000; Gutmann and Thompson, 1996; Smith, 2003).

National deliberative forums, such as the Senate and House of Representatives, have been envisaged as the proper site where climate change policy decisions gain democratic legitimacy. This view is espoused by, for example, the Australian Leader of the Opposition and the Greens political party, neither of which were convinced of the potential benefits of a citizens' assembly for climate change and mitigation responses proposed by the Prime Minister of Australia (SBS News 2010). Deliberative democrat Dryzek (2000) argues that formal institutions alone cannot constitute an effective deliberative system, as they are dependent on electoral responses in competitive electoral systems which do not contribute to deliberative capacity, but rather tend to stifle opinions. He defines deliberative capacity as the extent to which a political system possesses structures to host deliberations that are authentic, inclusive, and consequential (Dryzek, 2009). Authenticity refers to the capacity of deliberation to "induce reflection noncoercively, connect claims to more general principles, and exhibit reciprocity" (page 1382). This requires formal policy-making processes to strengthen connections with informal or nontraditional institutions and practices which perform a liberative function of displacing symbolic politics and promote reflection upon preferences and their transformation (Chambers, 2009; Gutmann and Thompson, 1996; Niemeyer, 2004).

The greater capacity to reflect and modify people's opinions as a result of their participation in deliberation is one dimension where ordinary citizens may make better deliberators than partisan political actors (Dryzek, 2010, page 158; see also Hendriks et al, 2007, pages 369-371). Authentic deliberation guided by the principle of reciprocity affirms the deliberative ideal that "citizens must provide reasons in terms that those with whom they disagree can accept" (Dryzek and Niemeyer, 2006, page 643; see also Gutmann and Thompson, 1996). Specific convictions and concerns should be articulated in ways that connect to alternative claims through their links to more general, shared principles of political life. Affirmative observations demonstrating an improving deliberative capacity can shed light on what designed deliberative forums ought to achieve in an informally constituted and empowered space for the production of collective decisions. 
However, what these links are and how they get shape in political deliberations remains unclear. A handful of empirical studies have provided details on the development of mutual understanding and impetus to evolve consensual decisions through deliberation. An important micropolitical process is the creation of cultural connections. Davies and Burgess (2004), for instance, highlighted the intention of deliberating citizens to understand their experiences and identities in relation to networks of expertise. Soma and Vatn (2010) noted the tendency of group participants to withdraw from personal and partial considerations when a 'citizen frame' was instituted. Others emphasised the construction of thoroughly considered preference. Goodin and Niemeyer (2003) affirmed the role of information-induced internal reflection, particularly in emancipating the deliberating individuals from symbolic distortions (Niemeyer, 2004; 2011). Group deliberation might also help mitigate epistemic and linguistic uncertainties among stakeholders (Liu et al, 2010). Multiple micropolitical processes contribute to the development of the consensual basis of public policy decision.

What remains contested is the relative importance of the different ways in which reflective experience can be induced. Empirical studies have indicated nuanced variations in conceptualising observations of mutual understanding among deliberating citizens. These variations can be related to the two ideal deliberative activities: discursive communication influenced by perceptions of trust and cultural norms; and epistemic enlightenment through clarification of facts and rational emancipation. Cooperative discourse has been advocated as an integration of analytic elements with discursive processes (Lennox et al, 2011; National Research Council, 2008; Renn, 2006; Stirling, 2006). As Dryzek (2010) observes, however, the time for truly comprehensive integrated statements of the essence of deliberative democracy may have gone. The theory is increasingly subject to systematic empirical testing, and this has exposed tension between its analytic and discursive requirements (Lo, 2011a). Reciprocity is one core element of the theory that has been associated with varied connotations. Further empirical evidence on this key aspect could shed light on the evaluative criteria of public deliberation and its potential impacts at an individual level.

In this paper we ascertain the basis of conflict and consensus observed from a deliberative process in an attempt to inform the theoretical debate on the processes of democratic deliberation. The concept of deliberative capacity is illustrated by showing the way that reciprocal understanding could be enhanced among individuals participating in the deliberative decision-making process and which contributed to an increased level of cooperation within the deliberative forum group. The inquiry is based on findings from an Australian deliberative forum about carbon pricing policy. In the next section we outline the debate on the proposed ETS and public views about emission mitigation strategies reported by research studies. The workshop design is then introduced, and the workshop process is described. We provide a brief report on survey responses, after which transcripts collected during the workshop are analysed and results presented. Consequent conceptual implications drawn from the workshop proceedings are presented in the discussion, and the conclusions follow.

\section{Background}

In Australia an ETS was officially proposed in late 2008 to provide economic incentives for emission mitigation, known as the Carbon Pollution Reduction Scheme (CPRS) (Department of Climate Change, 2008). An ETS involved setting an emission cap and selling permits to businesses and organisations to emit carbon dioxide at freely fluctuating market prices. Under the CPRS the government intended to provide free permits to selected trade-exposed, energy-intensive industries and to return the AUD11.5 billion earned from selling emission permits as compensation to minimise impacts on the economy by offsetting price rises. Free price variation of permit was envisaged to be restricted by an initial government-administered 
price cap set at AUD10 per permit, subsequently rising to AUD40 over time (chapter 8, page 37).

Some critics considered the amount of compensation and subsidies available to major polluters to be excessively generous (Curran, 2009; Spash, 2010; Spash and Lo, 2012). The price cap provision was seen as a compromise to potential economic efficiency by Jotzo and Betz (2009). The Greens political party opposed the lenient targets set out in the CPRS, while the opposition Liberal party was concerned with potential job losses and the impact on economic viability. Consequently, the CPRS failed to secure adequate parliamentary support in December 2009.

In view of the divisive public opinions, the Prime Minister, Julia Gillard, attempted to extend the national debate over alternative measures. In July 2010 she called for a high-profile 'citizens' assembly' as part of her election promise to gain community consensus on a price on carbon through designed deliberative activities among citizens. The citizens' assembly concept was abandoned less than three months later, in favour of a multiparty climate change committee consisting of members of Parliament (The Australian 2010).

During this period various alternatives, remedies, and complements to the ETS were proposed. A widely discussed alternative was the introduction of a carbon tax, thereby charging for each unit of emission directly produced. This was supported by Humphreys (2007) and Spash (2010) for its (i) lower administrative costs, (ii) lower potential for industrial manipulation, and (iii) greater certainty for businesses. In addition, voluntary carbon markets have been considered by the Australian government to complement establishment of an ETS. The National Carbon Offset Standard was introduced in July 2010 to promote standardisation (Department of Climate Change, 2009). Jotzo and Betz (2009) favoured an improved ETS that would have consistent access to international permit trading opportunities.

Increasingly, the general public have been found to be concerned about the possible economic impacts of radical actions proposed for climate mitigation and adaptation. According to the annual opinion polls by Hanson (2010, page 14), in $200668 \%$ of Australians agreed that global warming was a serious and pressing problem and immediate actions were needed, regardless of the significance of the costs. These figures contracted to $60 \%$ of respondents in $2008,48 \%$ in 2009 , and $46 \%$ in 2010 (page 14). The poll results indicate that $7 \%$ of respondents did not accept actions that might put the economy at risk and would support actions only after general public and political consensus was reached about the negative impacts of global warming. Approximately 8\% (2008) and 13\% of respondents (both 2009 and 2010) shared this view (page 14). The Climate Institute's (2010, page 11) survey noted a growth in tendencies to deny climate change effects - denialism. Although the majority of Australians (77\%) were convinced that climate change was due to human activities, more people tended to disagree over this claim in $2010(23 \%)$ than in $2009(16 \%)$.

Public preferences for the ETS have been found to be divided. Pietsch and McAllister (2010, page 225) found in their survey of 1000 participants that the ETS was positively received by the majority (58\%) of the Australians. While $29 \%$ strongly favoured the scheme, $22 \%$ also strongly opposed the ETS. Of those who described themselves as very well informed about climate change, a third strongly supported the ETS and a third strongly opposed the introduction of the ETS. Strong opinions outnumbered milder opinions, suggesting that a strongly opinionated minority within the population were opposed to the ETS. There was a tendency for polarisation of attitudes, which Pietsch and McAllister (2010) claim was accelerated by the successful knowledge diffusion from climate change sceptics and industrial lobby groups into the public arena. They also noted that the strong opponents may include those who accept the evidence of human-induced climate change but doubt that the proposed ETS is the right policy instrument to address climate change issues. 
Respondents of a national survey by Carson et al (2010) were almost evenly split on whether an ETS should apply initial exemption to the transport sector. Nevertheless, they expressed great concern about giving special treatment to energy-intensive sectors, even when told that this could minimise job disruptions. In their survey Carson et al included a trinary choice of achieving emission reductions using tradable permits, taxes, or tighter technology standards. Results indicated an overwhelming preference for technology standards $(57.7 \%)$ over permits $(25.1 \%)$ or taxes $(17.2 \%)$ (page 908). Support for taxes, nonetheless, rose to $22.5 \%$ and permits down to $23.7 \%$ when the respondents were more informed about the different mechanisms.

Seemingly, under persistent divisions within political and public spheres, consensual outcomes are difficult to attain without providing dialogue, discussion, and deliberation to nurture mutual understanding between actors. Against this political and policy backdrop the authors conducted a deliberative forum to understand more about the impact of dialogue and influence on people's decision making and choice of formal schemes to encourage greenhouse gas emissions reductions and form policies dedicated to mitigating factors implicated in global climate change. It was conducted a week after the Prime Minister's announcement of the prospective citizens' assembly, at which time the participants expressed great interest in the controversial media debate.

\section{The case study}

The 'Australian Climate Policy Forum' deliberative workshop was held on 31 July 2010 in Canberra. Twenty-four citizens participated, who were recruited randomly from the Canberra region via responses to a mailout questionnaire. Participant selection was based on perspectives about emission trading, expressed in a preliminary survey administered through e-mail, to ensure representation of key positions - that is, ETS, carbon tax, and climate scepticism. The selection process resulted in a narrow, unrepresentative demographic sample. As such, the findings from the workshop provide insights into the dynamics within the workshop setting, without being representative of the population as a whole. More males (fifteen) were in attendance than females (nine). Most were middle-aged and educated, working professionals. The homogeneity may be a consequence of the relatively narrow demographic profile of the region and failure to reach a larger population of potential participants. Twenty participants lived in the Australian Capital Territory, mainly Canberra, and four lived in New South Wales, mostly from the city of Goulburn.

During the workshop, participants were involved in a series of group discussions on carbon pricing and clean energy financing issues after scientific presentations of information relating to the topics under discussion. The objectives of the workshop were to evaluate current government efforts towards climate change, consider the future of the Australian emissions mitigation policy, and assess potential economic implications. Four specialists were involved as invited presenters to share information and knowledge related to dedicated themes, including:

(1) the science of climate change;

(2) the economic and policy implications of climate change;

(3) the international climate politics; and

(4) the economics of emission trading and carbon tax.

The presenters were allocated 30 minutes; and the final presentation, which focused on the mechanisms of various policy approaches and the strengths and weaknesses of the ETS and carbon tax, was allotted 45 minutes to respond to queries by workshop participants and provide more detailed information suited to the participant deliberation that followed the presentations. 
Group discussions occurred throughout the presentations. The first session focused on 'Concern about climate change', where the participants defined the problem at hand and expressed views about general issues, such as Australia's responsibility in greenhouse gas reduction and the relative importance of emission mitigation. The theme of the second session was 'Carbon pricing', which occurred after the emission trading presentation. The discussion explored the merits of the four possible carbon pricing arrangements: emission trading, carbon tax, voluntary carbon offsetting (where participants can voluntarily provide monetary contributions to schemes that reduce carbon emissions), and taking no action (where no carbon pricing on human activities is required). In the third session participants considered a range of financial issues under the theme of 'Financing low-emission energy technologies'. This session involved a focused discussion on willingness to financially contribute to research and development of low-emission energy technologies. Participants formed three groups to discuss each topic, with each group facilitated by a Commonwealth Scientific and Industrial Research Organisation (CSIRO) researcher.

Participants completed a questionnaire at the beginning and at the end of the workshop. Survey tasks included ordinal ranking of the above-mentioned four carbon pricing options (from most preferred to least preferred) and expressing willingness to pay (WTP) for emission mitigation. Group discussions were recorded, transcribed, and analysed in reference to the

Table 1. Stated preference of respondents.

\begin{tabular}{|c|c|c|c|c|}
\hline \multirow[t]{2}{*}{ Respondent } & \multicolumn{2}{|l|}{ Predeliberation } & \multicolumn{2}{|l|}{ Postdeliberation } \\
\hline & primary preference & WTP & primary preference & WTP \\
\hline$\overline{\text { Alan }}$ & $\operatorname{tax}$ & + & $\operatorname{tax}$ & + \\
\hline Brian & $\operatorname{tax}$ & + & $\operatorname{tax}$ & + \\
\hline Claire & $\operatorname{tax}$ & + & $\operatorname{tax}$ & + \\
\hline Cynthia & $\operatorname{tax}$ & + & $\operatorname{tax}$ & + \\
\hline Dan & voluntary offsetting & + & tax and ETS & + \\
\hline Dave & $\operatorname{tax}$ & + & $\operatorname{tax}$ & + \\
\hline Elaine & ETS & + & ETS & + \\
\hline George & ETS & not specified & ETS & + \\
\hline Helen & ETS & + & $\operatorname{tax}$ & + \\
\hline Howard & ETS & + & $\operatorname{tax}$ & + \\
\hline Ian & ETS & + & $\operatorname{tax}$ & + \\
\hline James & $\operatorname{tax}$ & + & $\operatorname{tax}$ & + \\
\hline John & ETS & + & ETS & + \\
\hline Kate & $\operatorname{tax}$ & + & $\operatorname{tax}$ & + \\
\hline Kevin & ETS & + & ETS & + \\
\hline Liana & $\operatorname{tax}$ & + & $\operatorname{tax}$ & + \\
\hline Mark & ETS & + & ETS & + \\
\hline Mike & no pricing & refused & $\operatorname{tax}$ & + \\
\hline Nancy & no pricing & refused & no pricing & + \\
\hline Phillip & $\operatorname{tax}$ & + & $\operatorname{tax}$ & + \\
\hline Ross & $\operatorname{tax}$ & + & $\operatorname{tax}$ & + \\
\hline Sarah & $\operatorname{tax}$ & + & $\operatorname{tax}$ & + \\
\hline Stephanie & $\operatorname{tax}$ & + & ETS & + \\
\hline Wilson & ETS & + & ETS & + \\
\hline
\end{tabular}

Notes: tax = carbon tax; ETS $=$ emission trading scheme; no pricing — no carbon pricing on human activities; ' + ' $=$ positive willingness to pay (WTP). 
deliberative dynamic, providing a delineation of the ways in which viewpoints converged during the workshop.

\section{Stated primary preference}

Survey data confirmed a clear stated preference for official carbon pricing, both before and after the information and deliberation process (table 1). A carbon tax was found to be most favoured, receiving twelve primary votes, three votes ahead of an emission trading proposal. Only three individuals preferred no official pricing of carbon or unofficial pricing through voluntary offset markets. An initial group preference emerged following the deliberative activities. Carbon tax received the majority of support post deliberation and was chosen by more people as the principal option, yielding a net increase from twelve to sixteen votes.

Initially, two subjects (Nancy and Mike) ${ }^{(1)}$ held opposing views by categorically rejecting the ideas of emission trading and carbon taxation. They saw no need for pricing carbon and declined the WTP request. The deliberation improved cooperation of sceptical individuals. Mike contributed to the increasing group support for the carbon tax option, and Nancy became more sympathetic to emission trading. Both returned a positive WTP, indicating a qualitative convergence in their WTP decisions.

\section{Observed deliberative dynamic}

In this section we report the verbal interaction amongst participants during formal discussions. On the basis of a qualitative analysis of transcripts, we outline how participants constructed their climate change discourses by reasoning, projecting boundaries to sharpen positions, and articulating requirements of their preferred climate change policy. Key conflicts encountered and shared concerns are highlighted in the following sections.

\section{Encountering conflict}

In some groups discussions began with palpable tension apparent. The information presented on the technical and policy dimensions of climate change was sufficient to allow people to form and/or reform weakly held opinions in response to uncertainties surrounding the topic. The discussions that followed indicated participants were aware of, and concerned about, the influence of climate scepticism in Australia. One of them, James, started his conversation with a cynical tone: "No climate sceptics here?", and Ross responded "Well there are some; there are people who are sceptical about it. They don't believe that it's happening at all." Those who were not professed sceptics but interacted with sceptical individuals in the general community tended to be cynical or even hostile towards sceptical and opposing viewpoints. For instance, when describing a local campaign promoting energy efficiency, Dave claimed they were "fighting climate change deniers", and Kevin echoed this sentiment immediately by referring to his own experience.

Mike had identified himself as a "denier" in a preworkshop correspondence:

"This has become a polarised argument amongst two distinct camps: those who believe that recordable global warming is not a result of human activity and those who believe that the emission of industrial carbon gases is directly the cause of irregular weather patterns ... . My views are more directly associated with the first camp."

The two 'camps' appeared to be limited by their opinions predicated upon competing beliefs. For example, the individuals committed to emission mitigation constructed their arguments mainly around moral virtues, indicated by phrases such as "science seems to be saying we ought to", "greatest moral challenge", and "we have a responsibility". They envisaged Australia as a role model for other nations to follow in emission mitigation. Moral outrage at ecological changes were expressed referring to the possibility that in the future

${ }^{(1)}$ All participant names reported are arbitrarily assigned to preserve participant anonymity. 
the Great Barrier Reef may severely suffer from temperature rises, consequently having an economic impact on ecotourism.

Sceptical individuals seemed to offer two main arguments. The first argument was the problem of incomplete evidence to substantiate anthropogenic climate change claims. Perceived uncertainties and limits of current knowledge have led to suspicion of the scientific propositions concerning the significance of the problem. For example, rather than denying the harmful effects of industrial emissions, doubts were expressed that the current level has reached a tipping point:

"So we have less of carbon dioxide, amongst other gases, absorption, so as you industrialise and farm more land there's less ground absorption. So everything you say Kevin is right, but it's grouped up now to what extent, what percentage?" (Mike).

The second argument was that Australia had made a minimal contribution to global climate change: "we are not the biggest polluters on Earth anyway, are we?" (Nancy).

Discernable conflict began to surface as people felt more comfortable with each other and became more expressive during the workshop proceedings. When Kevin, who favoured an ETS, tried to exclude the options of voluntary offsetting and carbon pricing from further consideration, Mike indicated his reluctance by saying "Yes, I give the no carbon pricing at this stage in time" and was seconded by Nancy: "I'm going with the last one too". Kate was also leaning toward this option, on the proviso that global initiatives were firstly to be put in place. A division unfolded as concerns about carbon pricing were further discussed and various opinions surfaced. Explicit disagreements between the two camps, notably between Mike and Kevin, indicated a heightened level of conflict. Putting a price on carbon was deemed to be unnecessary by Mike, who favoured direct regulations. The rebuttal from Kevin was that "There's no way we're going to get a reduction of carbon without a cost." At this point Mike no longer challenged the evidence of harmful greenhouse effect, but stressed the ineffectiveness of the proposed policy measures. His reply to Kevin's view concerning cost adjustment encountered strong reaction:

Mike: "That's just because you assume that there must be a punishment for the emission. Now, what we didn't discuss in there is that at this relative stage in the industry, particularly power generation that we're talking about, there's only a technological advance we can make. We've virtually hit the valley. At this stage in time in general 90 percent of the power that's generated in Australia cannot be improved upon or made more efficient."

Kate: "Yes it can."

Kevin: "I totally disagree with that. Totally disagree."

Mike: "With umpteen billion ..."

Kevin: "Not umpteen-well there's a number of ways you could do it. You can do it with renewable sort of energy. Well you may discount that, but there are a lot of people that don't discount that."

Milder disagreement was again observed in session 2 among individuals committed to emission mitigation, particularly when controversies about emission trading entered into the debate. For example, Alan and Elaine argued with each other over the feasibility and effectiveness of an emission cap, frequently introducing their arguments with 'but ....' to counter other's responses, indicating a clear difference in perspectives.

Varying levels of support for an ETS were observed in all groups, not only at the beginning of session 2 but also near the closure. This suggested that disagreement persisted. Yet a closer investigation indicated some emergence of common grounds. For example, when Alan and Howard exchanged views as to the commonality of the ETS and carbon tax, Kevin also pointed out a shared feature - that is, "the government is going to compensate you like welfare to make up for the increased costs." 


\section{Characterising problems: markets and trust}

Common grounds unfolded as the debate moved from expressions of personal preferences and stances to characterisation of policy limitations. Questions were raised and disappointments expressed as to the limited efforts towards emission mitigation made by major actorsnamely, businesses, governments, and the public. Expressed doubts and disappointments contained important shared subjective elements and contributed to temporary alliances and shared agreement between previously differing individuals. This occurred as participants reflected on the overwhelming concerns and limitations of ETS if relying on regulation by market systems.

The possibility of cheating and market manipulation was deemed to be the biggest issue surrounding ETS. For example, "I'd be wary of the ETS of market manipulation. We see how proficient traders are at developing new systems like what brought down, went on the global financial crisis, with the manipulations of the market" (Ian). Brian concurred: "to me all these market-based things, they leave open the option of rorting and that's what's happened in our society."(2) One of the sceptical individuals, Mike, remained unconvinced: "Well that methodology [of ETS] has got a pretty big downer for me because it's not controlled sufficiently by government from what I can see. It falls out into the hands of the private markets, and we lose control of our own sovereign rights." This was one remarkable occasion where an opponent of carbon pricing joined his nonsceptical counterparts.

Participants unanimously criticised government and political involvement. Some held a cynical attitude toward the government for its unsatisfactory record of official response: "they can't even do pink batts and you're wanting them to look after an emissions trading scheme? I mean, they couldn't even look after a carbon tax, let's be exact", ${ }^{(3)}$ said Philip. When prompted to evaluate the government's contributions to addressing climate change, Ian responded "It hasn't done anything", and Brian concurred and said "You're joking".

The discontent was extended to politicians in general. Failure to properly respond to climate change issues and develop mitigation plans was attributed to "playing politics". Some contended that politicians turned a deaf ear to the evidence of climate change, although a few disagreed with this statement. The participants were united in articulating a complaint that politics rather than the state of global environment was taken as the main game. Common grounds became more audible as cynical comments were shared within the group. Similarly, distrust in government has also been shown to occur in other areas of natural resource management.

\section{Articulating shared principles}

Perspectives converged at the level of broad principles. Having discerned shared concerns, individuals were able to jointly articulate criteria for a preferred carbon pricing policy. The criteria included factors of effect certainty and accountability. All groups demanded clear emission reduction targets, dedicated use of the raised funds, accountability for allocation systems, and guaranteed reduction in emissions. Advocates of ETSs generally were not in favour of carbon taxation because "It doesn't give a guarantee of the emissions reduction" (Elaine), whereas an ETS is "an almost guaranteed way of reducing a very specific amount of pollution" (John). Carbon tax supporters wanted similar guarantees. Dedicated use of raised revenue 'proved' to be a key criterion reiterated within all groups.

(2) 'Rorting' is a term used in Australia and New Zealand. It refers to the action of defrauding, particularly relating to a financial impropriety of a government programme.

(3) 'Pink batts' refers to the government's home insulation programme, where insulation using pink batts (made from lightweight, flexible, and resilient glasswool) were laid in home ceilings to reduce energy consumption and greenhouse gas emissions. The nationwide insulation scheme was abandoned quickly following the deaths of four workers, house fires, and many maintenance interventions. 
The sceptical individuals did not oppose spending more money on the development of low-emission technologies. They too requested strict dedication:

"can we be sure that all of those levies do go towards this research and development and assistance in construction of wind farms or whatever it might be. Not disappear back into consolidated revenue" (Mike).

An ETS was seen to provide more certainty on emissions mitigation, whereas a carbon tax seemingly offered greater transparency over the use of the raised revenue. Central to both camps were the questions 'where is the money going?' and 'what is going to be achieved with it?' When the discussion moved from intended financial support to low-emission technologies (session 3), advocates of ETS and carbon tax articulated transparency and accountability concerns. For example, Ian, who shifted in preference from ETS to carbon tax, became aligned with his carbon tax counterparts' arguments:

Ian: "So we'd have to have goals. So what we're going to do in - this is what you're going to pay and this is what you're going to get in ten years' time."

Cynthia: "Yes, and they're measured on those targets."

Ian: "Yes, and every five years someone has to report to the Parliament on how close we are to achieving those goals."

James: "All the money is dedicated to establishing a low carbon economy."

Kevin, a vocal speaker for ETS, also stressed that "it depends on how it's being used and how you can show me that it's really been of benefit to this country." A group member, Dave, argued for carbon tax with the same concerns:

"If the government can get a solution that's very clearly outlined-where does the money go, how much it is, who will pay how much, and who will not have to pay because they don't have the income - then this could really be a good thing. But if they don't explain it properly, people will probably say no-as long as we don't know where the money goes to, then we're not part of it."

Dave agreed with Mark, an ETS advocate, who suggested examples of inappropriate use of money by saying

"There should be a bit of accountability, and it should not be about propping up an existing industry sector like coal."

A related factor frequently mentioned was trust. As emission mitigation does not have tangible benefits or visible consequences, assurance on proper use of funds and outcomes depends on the reliability and credibility of the collector and manager of these funds. In many instances participants appeared hesitant to endorse a particular policy option because of their lack of trust in businesses and in government bureaucrats. They suggested that carbon pricing could provide electricity companies with a legitimate reason to raise prices and doubted that the companies would genuinely and properly allocate the money to tackle climate change. Evidence included declining willingness to contribute under a hypothetical scenario, where the utilities could use the raised funds at their discretion-for example, credited as consolidated revenue. More generally, the notion of emission trading was deemed to be an inappropriate transactional method. As Liana explained, with agreement from Dave, "This trading scheme is too vulnerable to shonky dealing, shonky offsets, and weird sorts of trading loopholes." This finding may be linked to prosecutory worldviews as described by Alexander et al (2012), where people are concerned that new policies do not avail system 'cheats' an avenue of benefit, and that new schemes implicated in natural resource management are fair and generally acceptable to established social behavioural norms.

Lack of trust also contributed to the unpopularity of voluntary offsetting: "when you tick the box when you buy an airline ticket, like carbon credits, that money is just banked 
somewhere it's not actually doing anything" (Howard). The reliability of the market systems was called into doubt:

John: "I've sort of generally always on principle, refused to buy them [carbon offsets]. I don't know the system they're going to. They always do research into what it's going to, but I really don't know where that money is going to."

Brian: "It's a lack of trust."

John: "Yeah, I just don't trust the system."

Mike had little disagreement on this point: "No. You can't trust business to actually take the place of government. There are certain things that government has a total responsibility for, and one of them is the mechanism - a control of price."

While everyone seriously considered issues of trust to be important, they differed in those to whom they attributed trust. Although carbon tax supporters tended to be suspicious of the markets, some failed to be reassured by the government: "I don't trust the government-I don't want it to go into a general fund and they feel like they can spend it on carbon capture, which I don't believe in" (Dave). Kevin trusted the market, and this factor contributed to his argument for an ETS: "My approach would be ETS, basically because I believe that the market will come up with more creative ideas and I believe it's the most efficient way of going about it." Likewise, Brian chose the markets in favour of the bureaucrats: "we can have a trading scheme, and I'm against a carbon tax simply because [of] the bureaucrat."

The importance of trust was twofold. Firstly, it significantly influenced the policy choice of the groups. Secondly, the three groups - that is, advocates of ETS and carbon tax and the sceptical individuals - somehow merged into two groups. As Dave observed: "I think of all these things we're discussing today, the matter of trust seems really important. We all do not really seem to trust governments. Some of us don't trust the markets." Concerns over trust made the discursive boundaries more permeable. Mike, initially showing a sceptical attitude, leant more toward tax supporters jointly arguing against the market believers:

Mike: "A form of carbon tax, I think."

Kevin: "I disagree; you can say what's the ETS because I believe in a market."

Helen: "You could split them into four."

Sarah: "I was just thinking about that, I thought we could actually divide this up a bit because that's okay."

Mike: "I don't trust the markets."

Kevin: "Well, I do."

Discussions surrounding certainty and accountability issues indicated greater shared agreement than was shown in trust discussions. Consensus occurred over the legitimacy of the principles of reliability and certainty/accountability. These principles facilitated the ensuing agreement to pay for emission mitigation. A causal relationship was evidenced: "The more transparent it is, the more I'd be willing to pay. You've got to damn well make it transparent, not just pull my leg" (Kevin). This was also articulated in terms of guarantee of end use: "that the amount of money depends on what it's being used for" (Elaine).

Participants under disagreement identified subjective connections through these terms of acceptance, although the underlying principles were sometimes subject to different interpretations. For example, reliability of institutions was considered by all to be important. Yet while Dave did not trust the government, Mike appeared more confident; and Kevin was optimistic about private markets, but his group members seemed unconvinced. The divided perspectives came to overlap at an abstract level where mutual recognition and agreement were more likely to develop. This raised prospect for consensus, as Kevin concluded: "I'm against it but I would say that the carbon tax would be the preferred option of us all." 


\section{Communicative role of shared frame of reference}

Public scepticism or resistance to active climate protection has been seen to flourish in the larger society (Climate Institute, 2010; Fleming and Vanclay, 2009). Communicative and behavioural hurdles have to be avoided or removed to enable fruitful deliberation between sceptical and nonsceptical groups. As the case study has shown, sceptical positions softened when adherents joined the rest of the group in launching an attack on businesses. Capacity for discursive alignment can be built upon shared social experiences or rhetoric, as Dryzek (2010b) and O'Neill (2007) suggest.

The perceived dichotomy of two camps observed from the outset of discussions indicated the existence of established yet competing perspectives. Frustration expressed in the discussions was an active rebuttal of the existing political processes. These dispositions, which could have threatened the collaboration by strengthening a sense of indifference and encouraging withdrawal from the search for an agreed group preference, were not reinforced over the course of deliberation. Shared general principles, concerning the legitimacy of policy mechanisms, were discerned through a joint process of uncovering problems associated with the policy community. Communication along these lines allowed for an alignment of differing individual perspectives. A few participants eventually shifted to the majority position, whilst others came to respect contrasting opinions. Cooperative capacity was enhanced, which may have contributed to the increasing support for the carbon tax option and improved WTP on the part of the sceptical individuals.

There are a number of possible reasons why the sceptics could have modified their stance. The change in opinion of the sceptics may have been because the process treated the sceptical participants with respect and gave them the opportunity to express their views in a nonthreatening forum where they could learn from others. The presentations by experts may have increased the knowledge of the sceptics, presenting important information that was previously unknown. It is also possible that being in the minority group in a nonthreatening forum could have resulted in social pressure to conform to the majority opinion.

Successful participatory dialogue can identify and take citizens to discursive spaces in which competing options, values, or discourses can be communicated effectively (Dryzek, $2000 ; 2010 \mathrm{~b})$. Instead of pitting themselves against each other in conflict or generalising about alternatives aiming for universal acceptance, a public deliberation should be designed to explore bridging elements that impress the divergent groups. Trust in institutions, for example, played such a role. The argument that implementation of a carbon tax would rest on trusted and familiar administrative mechanisms appealed to stated opponents of carbon tax as it matched their priority of trust concerns. As the legitimacy of these concerns was mutually recognised, they allowed reasons for endorsing the tax option to be couched in terms that its opponents found acceptable. This acceptance received their reflective assent built upon the knowledge that their key concerns had been recognised and addressed. It was at least partially derived from the deliberative virtue of reciprocity.

Appeal to shared political experience (with the government and energy companies) made different arguments more accessible. It was instrumental to the making and listening of alternative representation claims and demonstrated a similar communicative role as effective as shared community memories (Burgess et al, 1988) and shared national identity (HartzKarp et al, 2010). Citizens' attempts to build up cultural connections with trusted experts, as observed by Davies and Burgess (2004), contributed to effective production of collective decisions. Agreement across parties to a dispute may be facilitated in a deliberative arena by demonstrating the ways in which individuals are similarly situated in morally or politically relevant respects (Guttman and Thompson, 1996). Reciprocity entails an attempt to strengthen relations of knowledge or experience in search of apprehensible terms of reference that allow 
generalisation of divergent dispositions. Our study adds to the literature by affirming the communicative role of politically resonant experience and expectations. It lends empirical support to the call for invocation of shared cultural experiences and the use of culturally resonant symbols to improve climate change communication (Moser and Dilling, 2007).

Convergence in values is not regarded as a necessary condition of discursive alignment (Lo, 2013). Mutual respect is compatible with enduring communicated differences in normative dispositions. Our study does not offer clear evidence on the emancipatory effect of deliberation, which involves "correcting the distortion of public will" (Niemeyer, 2011, page 128). Niemeyer believes that lack of 'intersubjective consistency' may be associated with symbolic distortions, where deliberation citizens' expressed preferences tend not to properly reflect the ends that they would have liked to achieve. High levels of intersubjective consistency are suggested to be an indicator of good deliberation. Quantitative data collected from our deliberative forum, however, statistically indicated the opposite trend of diminishing intersubjective consistency (Lo, 2011b). Seemingly, the quantitative analysis suggests a 'distortion' of public will, which nevertheless came with a commendable gain in mutual understanding. Identifying generalisable interests, as demonstrated, appears to be a different objective from correcting preferences. Dedicated empirical research is needed to further examine the discursive and epistemic arguments for public deliberation.

\section{Conclusion}

Twenty-four Australian citizens gathered to discuss issues about carbon pricing. They differed about the need and means for carbon pricing. Common grounds were then discerned through articulating shared policy considerations including trustfulness and accountability. Establishing a reliable, trusted institution for handling the financial matters involved proved to be a priority shared among participants. These shared political expectations fostered reciprocal communication and cooperation by holding diverse individuals within a narrative or storyline. The deliberation resulted in a majority support for the notion of a carbon tax. Those remaining unconvinced expressed respect for the group preference, and the sceptical individuals indicated an increasing level of WTP for mitigation. This provided impetus for more substantial agreements than would be required when formalising binding decisions from policy deliberations.

The research has shown what kind of communication public deliberation ought to achieve to produce consensual outcomes. Citizens who compete to advise on what course of action is needed may engage in a policy dialogue more effectively on the basis of more general, shared expectations about political life. Appeals to similar political, social, or geographical experiences could make conflict more tractable and dialogue more fruitful. Competing options couched in discursive terms compatible with each other may then appear more accessible to their opponents. Deliberative inquiry about issues of national importance, such as climate change, would benefit from a greater understanding of what constitutes the discursive channels for communication between differently situated actors. The democratic quality of public deliberation should be assessed in terms of the capacity for participants to reflect, modify, or generalise their beliefs in recognition of the deliberative virtues of respect and reciprocity.

Public deliberative forums may be a better site for deliberating public policy than formal political institutions in terms of the potential for mutual recognition among deliberators. Democratic legitimacy can be achieved by participation in authentic deliberation on the part of those subject to a collective decision, in contrast to the traditional definitions couched in electoral and constitutional terms. Formal policy-making processes that reward adversarial politics do not accommodate the virtue of reciprocity, which is increasingly seen as a function of democratic legitimacy in plural societies. From this perspective, citizen forums as a 
form of minipublic may produce decisions that are more responsive to the different priorities of people and are more democratic than partisan politics dominated by elites.

Acknowledgments. We would like to acknowledge the efforts of the twenty-four participants of the workshop. Thanks also to Mark Stafford Smith, Steve Hatfield-Dodds, Hayley Stevenson, and Andrew Reeson, whose presentations were well received and informative. Nick Abel's comments on an earlier draft of this paper are appreciated. The research project is funded by a CSIRO postgraduate scholarship.

\section{References}

Alexander K S, 2010, "Community preferences for uses of stormwater after treatment and storage in aquifers in South Australia", conference paper presented to 'Water Reuse and Desalination: Water Scarcity Solutions for the 21st Century', 15-17 November, Sydney, https://publications.csiro.au/rpr/download?pid=csiro:EP113751\&dsid=DS2

Alexander K S, Ryan A, Measham T G, 2012, "Managed retreat of coastal communities: understanding responses to projected sea level rise" Journal of Environmental Planning and Management 55 409-433

Amundsen H, Berglund F, Westskog H, 2010, "Overcoming barriers to climate change adaptation- a question of multilevel governance?" Environment and Planning C: Government and Policy $\mathbf{2 8} 276-289$

Burgess J, Harrison C M, Limb M, 1988, "People, parks and the urban green: a study of popular meanings and values for open spaces in the city" Urban Studies $25455-473$

Carson R T, Louviere J J, Wei E, 2010, “Alternative Australian climate change plans: the public's views" Energy Policy 38 902-911

Chambers S, 2009, "Rhetoric and the public sphere: has deliberative democracy abandoned mass democracy?" Political Theory 37 323-350

Climate Institute, 2010 Climate of the Nation: Australian's Attitudes towards Climate Change and Its Solutions http://www.climateinstitute.org.au/ images/reports/climateofthenation_august2010.pdf

Curran G, 2009, "Ecological modernisation and climate change in Australia" Environmental Politics $18201-217$

Davies G, Burgess J, 2004, “Challenging the 'view from nowhere': Citizen reflections on specialist expertise in a deliberative process" Health and Place 10 349-361

Department of Climate Change, 2008 Carbon Pollution Reduction Scheme: Australia's Low Pollution Future (Commonwealth of Australia, Canberra)

Department of Climate Change, 2009 National Carbon Offset Standard (Commonwealth of Australia, Canberra)

Dryzek J S, 2000 Deliberative Democracy and Beyond: Liberals, Critics, Contestations (Oxford University Press, Oxford)

Dryzek J S, 2009, "Democratization as deliberative capacity building" Comparative Political Studies 42 1379-1402

Dryzek J S, 2010 Foundations and Frontiers of Deliberative Governance (Oxford University Press, Oxford)

Dryzek J S, Niemeyer S, 2006, "Reconciling pluralism and consensus as political ideals" American Journal of Political Science 50 634-649

Few R, Brown K, Tompkins E L, 2007, "Public participation and climate change adaptation: avoiding the illusion of inclusion" Climate Policy 7 46-59

Fleming A, Vanclay F, 2009, "Discourses of climate change: understanding farmer resistance", in Climate Change in Regional Australia: Social Learning and Adaptation Eds J Martin, M Rogers, C Winter (Victoria Universities Regional Research Network Press, Ballarat) pp 155-176

Goodin R E, Niemeyer S J, 2003. "When does deliberation begin? Internal reflection versus public discussion in deliberative democracy" Political Studies 51 627-649

Gutmann A, Thompson D, 1996 Democracy and Disagreement (Belknap Press, Cambridge, MA)

Hanson F, 2010 The Lowy Institute Poll 2010 Lowy Institute for International Policy, Sydney

Hartz-Karp J, Anderson P, Gasti J, Felicetti A, 2010, “The Australian citizens' parliament: forging shared identity through public deliberation" Journal of Public Affairs 10 353-371 
Hendriks C M, Dryzek J, Hunold C, 2007, “Turning up the heat: partnership in deliberative innovation" Political Studies 55 362-383

Hobson K, Niemeyer S, 2011, "Public responses to climate change: the role of deliberation in building capacity for adaptive action" Global Environmental Change 21 957-971

Hulme M, 2009 Why We Disagree about Climate Change: Understanding Controversy, Inaction and Opportunity (Cambridge University Press, New York)

Humphreys J, 2007 Exploring a Carbon Tax for Australia The Centre for Independent Studies, Sydney

Jotzo F, Betz R, 2009, “Australia's emissions trading scheme: opportunities and obstacles for linking" Climate Policy 9 402-414

Krause R M, 2011, "Symbolic or substantive policy? Measuring the extent of local commitment to climate protection" Environment and Planning C: Government and Policy 29 46-62

Lennox J, Proctor W, Russell S, 2011, "Structuring stakeholder participation in New Zealand's water resource governance" Ecological Economics 70 1381-1394

Leviston Z, Walker I A, 2010 Baseline Survey of Australian Attitudes to Climate Change: Preliminary Report Climate Adaptation National Research Flagship, CSIRO, Canberra

Liu S, Proctor W, Cook D, 2010, "Using an integrated fuzzy set and deliberative multi-criteria evaluation approach to facilitate decision-making in invasive species management" Ecological Economics 69 2374-2382

Lo A Y, 2011a, "Analysis and democracy: the antecedents of the deliberative approach of ecosystems valuation" Environment and Planning C: Government and Policy 29 958-974

Lo A Y, 2011b Deliberative Monetary Valuation as a Political-Economic Methodology: Exploring the Prospect for Value Pluralism with a Case Study on Australian Climate Change Policy unpublished $\mathrm{PhD}$ thesis, School of Politics and International Relations, Australian National University, Canberra

Lo A Y, 2013, “Agreeing to pay under value disagreement: reconceptualizing preference transformation in terms of plurism with evidence from small-group deliberations on climate change" Ecological Economics 87 84-94

McCrum G, Blackstock K, Matthews K, Rivington M, Miller D, Buchan K, 2009, “Adapting to climate change in land management: the role of deliberative workshops in enhancing social learning" Environmental Policy and Governance $19413-426$

Marks J S, 2006, "Taking the public seriously: the case of potable and non-potable reuse" Desalination 187 137-147

Moser S C, Dilling L, 2007, "Toward the social tipping point: creating a climate for change", in Creating a Climate for Change: Communicating Climate Change and Facilitating Social Change Eds S C Moser, L Dilling (Cambridge University Press, Cambridge) pp 491-516

National Research Council, 2008 Public Participation in Environmental Assessment and Decision Making (National Academies Press, Washington, DC)

Nerlich B, 2010, “'Climategate': paradoxical metaphors and political paralysis” Environmental Values 19 419-422

Niemeyer S, 2004, "Deliberation in the wilderness: displacing symbolic politics" Environmental Politics 13 347-372

Niemeyer S, 2011, "The emancipatory effect of deliberation: empirical lessons from mini-publics" Politics and Society 39 103-140

O'Neill J, 2007 Markets, Deliberation and Environment (Routledge, London)

Oreskes N, Conway E M, 2010 Merchants of Doubt: How a Handful of Scientists Obscured the Truth on Issues from Tobacco Smoke to Global Warming (Bloomsbury Press, New York)

Osberghaus D, Dannenberg A, Mennel T, Sturm B, 2010, "The role of the government in adaptation to climate change" Environment and Planning C: Government and Policy 28 834-850

Pietsch J, McAllister I, 2010, “ 'A diabolical challenge': public opinion and climate change policy in Australia” Environmental Politics 19 217-236

Pitt D, 2010, "The impact of internal and external characteristics on the adoption of climate mitigation policies by US municipalities" Environment and Planning C: Government and Policy 28 851-871 
Renn O, 2006, "Participatory processes for designing environmental policies" Land Use Policy $2334-43$

SBS News 2010, "Libs, Greens slam citizens' assembly on climate", 23 July, http://www.sbs.com.au/vote2010/news/1308787/ Labor's-climate-plan-is-camouflage:-Abbott

Smith G, 2003 Deliberative Democracy and the Environment (Routledge, London)

Soma K, Vatn A, 2010, "Is there anything like a citizen? A descriptive analysis of instituting a citizen's role to represent social values at the municipal level" Environmental Policy and Governance 20 30-43

Spash C L, 2010, "The brave new world of carbon trading" New Political Economy 15 169-195

Spash C L, Lo A Y, 2012, “Australia's carbon tax: a sheep in wolf's clothing?” The Economic and Labour Relations Review $\mathbf{2 3}$ 67-86

Stangellini P S L, 2010, "Stakeholder involvement in water management; the role of the stakeholder analysis within participatory processes" Water Policy 12 675-694

Stirling A, 2006, "Analysis, participation and power: justification and closure in participatory multicriteria analysis" Land Use Policy 23 95-107

The Australian 2010, "Gillard PM dumps citizens assembly as Labor, Greens strike alliance deal", 1 September, http://www.theaustralian.com.au/news/ labor-greens-strike-alliance-deal-for-stablegovernment/ story-e6frg6n6-1225912672100 